\title{
ПРОДУКЦИОННАЯ МОДЕЛЬ В ПРИНЯТИИ СУДЕБНЫХ РЕШЕНИЙ
}

\author{
Т. Ю. Харченко, И. Е. Воронина \\ Воронежский государственный университет
}

Поступила в редакцию 29.01.2018 г.

\begin{abstract}
Аннотация. Рассматриваются особенности разработки продукционных правил для алгоритма Мамдани для создания формальной процедуры поддержки принятия решений в уголовном судопроизводстве. Результаты исследования предполагается использовать при разработке тренажера для учебных систем и профессиональной деятельности.

Ключевые слова: продукционные правила, уголовное право, экспертная оценка, принятие решений.

Annotation. The article describes the development of production rules in the Mamdani algorithm for the development of formal procedure to support in making judicial decisions in criminal low. Results of research are the basis for the development of a simulator for the learning systems and professional activities.
\end{abstract}

Keywords: production rules, criminal law, expert rating, decision-making.

\section{ВВЕДЕНИЕ}

После выявления субъективной составляющей, присутствующей при вынесении итоговой меры пресечения в уголовном судопроизводстве, возникла идея создания как модели оценки результатов решения, так и процедуры поддержки принятия судебных решений. Субъективная составляющая заключается в разнице в итоговом наказании в делах, рассмотренных по одному и тому же пункту одной и той же части одной и той же статьи УК РФ [1]. Она выражается как в самом виде наказания, так и в размере наказания в годах, например, в одном деле вынесен приговор о лишении свободы сроком на 5 лет, в другом приговоре по аналогичному делу вынесен приговор о лишении свободы сроком на 7 лет.

В связи со сложившейся ситуаций, задача создания модели принятия решений в уголовном судопроизводстве, которая могла бы стать основой программных средств, представляется весьма актуальной. Такие средства могут выступать не только в роли своеобразного «тренажера», применяться в учебных целях,

() Харченко Т. Ю., Воронина И. Е., 2018 но и послужить для выявления «узких мест» законодательства, тем самым способствуя совершенствованию юридической техники.

В связи с тем, что принятие судебного решения носит субъективный характер (в отношении уголовных дел «судья, присяжные заседатели, а также прокурор, следователь, дознаватель оценивают доказательства по своему внутреннему убеждению, основанному на совокупности имеющихся в уголовном деле доказательств, руководствуясь при этом законом и совестью» - ч. 1 ст. 17 УПК РФ), не может быть и речи о какой-либо формализации решений. Поэтому предложения по созданию методик исследования проблемы и разработка на их основе средств автоматизации способствуют минимизации субъективности при принятии судебных решений и уменьшению коррупционной составляющей (актуальность вопроса высока также и в связи с тем, что в ряде статей Уголовного кодекса Российской Федерации [2] нет нижней границы наказания).

Для разработки формальной процедуры поддержки принятия судебных решений предлагается применить поэтапный подход [3].

Также предлагается подход к вычислению меры пресечения и определению коэффициен- 
тов смягчающих и отягчающих обстоятельств. Производились вычисления для одной меры пресечения - лишение свободы, которое измеряется в годах. Применительно к этой мере пресечения был выявлен наиболее полный список смягчающих и отягчающих обстоятельств, им, в соответствии с вычислениями [3], присвоены коэффициенты тяжести, которые влияют на итоговый размер наказания.

Были предложены два подхода к вычислению итоговой меры пресечения: количественный и качественный. Первый подход относится к количественным мерам пресечения, таким как: лишение свободы на определенный срок; арест; содержание в дисциплинарной воинской части; ограничение свободы; принудительные работы; исправительные работы; обязательные работы; штраф; пожизненное лишение свободы [4].

Второй подход относится к качественным мерам пресечения, таким как: ограничение по военной службе; лишение права занимать определенные должности или заниматься определенной деятельностью; лишение специального, воинского или почетного звания, классного чина или государственных наград.

Кроме того, в УК РФ наказания подразделяются на основные и дополнительные. Поэтому, в одном уголовном деле могут применяться сразу два подхода - количественный и качественный.

Для количественного подхода выявлены зависимые и независимые переменные, к зависимой переменной (итоговая мера пресечения) предложена формула вычисления [4].

\section{ПОСТРОЕНИЕ ПРАВИЛ}

Так как для вынесения решения по делу необходимо, чаще всего, оценивать несколько факторов, которые влияют на итоговый размер наказания, предлагается использовать алгоритм Мамдани. Такой алгоритм описывает последовательно повторяющиеся этапы, при этом каждый этап получает на вход значения, полученные в предыдущем этапе [5].

Использование алгоритма также обусловлено тем, что в нем на промежуточных этапах можно использовать элементы нечеткой логики и теорию нечетких множеств, вводить лингвистические переменные, присваивать им числовые ранги, на выходе же получая количественные значения [6]. Например, пусть $a_{1}, a_{2}, \ldots, a_{n}$ - сведения о совершенном преступлении и его квалификации; $b_{1}, b_{2}, \ldots, b_{n}-$ наличие смягчающих обстоятельств и их виды; $c_{1}, c_{2}, \ldots, c_{n}$ - наличие отягчающих обстоятельств и их виды; $k_{1}, k_{2}, \ldots, k_{n}$ - коэффициенты тяжести обстоятельств; max - максимальный размер наказания, min - минимальный размер наказания. Есть экспертная оценка значимости (влияния) смягчающего и отягчающего обстоятельства на размер наказания. Она может быть получена от судей или следователей (выступающих в роли экспертов), которые непосредственно имеют дело с оценкой обстоятельств. Формализовать данную оценку можно с помощью лингвистической переменной $\langle\beta, T, X, G, M\rangle$, где

$\beta$ - смягчающее (отягчающее) обстоятельство;

$T$ - \{«обстоятельство не влияет (минимально влияет) на размер наказания», «обстоятельство умеренно влияет на размер наказания», «обстоятельство сильно влияет на размер наказания»);

$$
X=[-1 ; 1]
$$

$G$ - процедура образования новых термов при помощи логических связок и модификаторов. Например, «обстоятельство максимально влияет на размер наказания»;

$M$ - процедура задания на универсуме $X=[-1 ; 1]$ значений лингвистической переменной, т. е. термов из множества $T$.

Для реализации алгоритма сформулируем продукционные правила на основании следующей информации:

1. Сведения о совершенном преступлении (преступлениях).

2. Квалификация преступления (статья УК РФ).

3. Наличие смягчающих обстоятельств и их виды.

4. Наличие отягчающих обстоятельств и их виды.

5. Коэффициенты тяжести обстоятельств.

6. Размер минимального наказания по данному виду преступления. 
7. Размер максимального наказания по данному виду преступления.

Для всех статей Уголовного кодекса [2] общие правила можно разделить на две группы: для наказаний количественных и наказаний комбинированных (количественные с качественными).

Для наказаний количественных (арест, лишение свободы (в годах, месяцах)).

$a_{1}, a_{2}, \ldots, a_{n}-$ сведения о совершенном преступлении и его квалификации;

$b_{1}, b_{2}, \ldots, b_{n}$ - смягчающие обстоятельства;

$c_{1}, c_{2}, \ldots, c_{n}$ - отягчающие обстоятельства;

min - минимальный размер наказания;

max - максимальный размер наказания;

$k_{1}, k_{2}, \ldots, k_{n}-$ вес обстоятельств (смягчающих и отягчающих).

Правило 1:

If $\left(a_{1}\right.$ and $a_{2}$ and $\left.\ldots a_{n}\right)$ and

$\left(b_{1}\right.$ and $b_{2}$ and $\left.\ldots b_{n}\right)$ then ( $\left.\mathrm{min}\right)$;

Правило 2:

If $\left(a_{1}\right.$ and $a_{2}$ and $\left.\ldots a_{n}\right)$ and

$\left(c_{1}\right.$ and $c_{2}$ and $\ldots c_{n}$ ) then (max);

Правило 3:

If $\left(a_{1}\right.$ and $a_{2}$ and $\left.\ldots a_{n}\right)$ and

$\left(b_{1}\right.$ and $b_{2}$ and $\left.\ldots b_{n}\right)$ and

$\left(c_{1}\right.$ and $c_{2}$ and $\ldots c_{n}$ ) then

$\left(\min +(\max -\min ) *\left(k_{1}+k_{2}+\ldots k_{n}\right)\right)$;

Правило 4:

If $\left(a_{1}\right.$ and $a_{2}$ and $\left.\ldots a_{n}\right)$ and

(b and $b_{2}$ and $\ldots b_{n}$ ) then

$\left(\min +(\max -\min ) *\left(k_{1}+k_{2}+\ldots k_{n}\right)\right)$.

Для наказаний комбинированных - количественные с качественными (например, лишение свободы + лишение права заниматься определенной деятельностью).

$a_{1}, a_{2}, \ldots, a_{n}$ - сведения о совершенном преступлении и его квалификации;

$b_{1}, b_{2}, \ldots, b_{n}$ - смягчающие обстоятельства;

$c_{1}, c_{2}, \ldots, c_{n}$ - отягчающие обстоятельства;

min - минимальный размер наказания;

max - максимальный размер наказания;

$k_{1}, k_{2}, \ldots, k_{n}-$ вес обстоятельств (смягчающих и отягчающих);

quality - качественное наказание.

\section{Правило 1:}

If $\left(a_{1}\right.$ and $a_{2}$ and $\left.\ldots a_{n}\right)$ and

( $b_{1}$ and $b_{2}$ and $\ldots b_{n}$ ) then ( $\mathrm{min}$ );

Правило 2:

If $\left(a_{1}\right.$ and $a_{2}$ and $\left.\ldots a_{n}\right)$ and

$\left(c_{1}\right.$ and $c_{2}$ and $\ldots c_{n}$ ) then max and quality;

Правило 3:

If $\left(a_{1}\right.$ and $a_{2}$ and $\left.\ldots a_{n}\right)$ and

$\left(b_{1}\right.$ and $b_{2}$ and $\left.\ldots b_{n}\right)$ and

$\left(c_{1}\right.$ and $c_{2}$ and $\left.\ldots c_{n}\right)$ then

$\left(\left(\min +(\max -\min ) *\left(k_{1}+k_{2}+\ldots k_{n}\right)\right)\right.$

and quality* $\left.\left(k_{1}+k_{2}+\ldots k_{n}\right)\right)$;

Правило 4:

If $\left(a_{1}\right.$ and $a_{2}$ and $\left.\ldots a_{n}\right)$ and

$\left(b_{1}\right.$ and $b_{2}$ and $\ldots b_{n}$ ) then quality;

Правило 5:

If $\left(a_{1}\right.$ and $a_{2}$ and $\left.\ldots a_{n}\right)$ and

$\left(b_{1}\right.$ and $b_{2}$ and $\ldots b_{n}$ ) then min and quality;

Правило 6:

If $\left(a_{1}\right.$ and $a_{2}$ and $\left.\ldots a_{n}\right)$ and

$\left(b_{1}\right.$ and $b_{2}$ and $\ldots b_{n}$ ) then

$\left(\min (\max -\min ) *\left(k_{1}+k_{2}+\ldots k_{n}\right)\right)$.

Для статей уголовного кодекса с большим количеством пунктов и разницей в наказаниях возникли трудности с определением продукционных правил. Поэтому для каждой статьи уголовного кодекса должны быть сформулированы дополнительные правила. И для квалификации преступлений по совокупности статей будут также действовать отдельные.

Пример продукционных правил для квалификации преступления по ст. 111 УК РФ Умеренное причинение тяжкого вреда здоровью.

БАЗА ДАННЫХ (подусловия).

Квалификация:

$\boldsymbol{a}_{1}$ - умышленное причинение тяжкого вреда здоровью, опасного для жизни человека, или повлекшего за собой потерю зрения, речи, слуха либо какого-либо органа или утрату органом его функций, прерывание беременности, психическое расстройство, заболевание наркоманией либо токсикоманией, 
или выразившегося в неизгладимом обезображивании лица, или вызвавшего значительную стойкую утрату общей трудоспособности не менее чем на одну треть или заведомо для виновного полную утрату профессиональной трудоспособности, - наказывается тишением свободь на срок до восьми лет;

$\boldsymbol{a}_{2}$ - те же деяния (умышленное причинение тяжкого вреда здоровью), совершенные: в отношении лица или его близких в связи с осуществлением данным лицом служебной деятельности или выполнением общественного долга; в отношении малолетнего или иного лица, заведомо для виновного находящегося в беспомощном состоянии, а равно с особой жестокостью, издевательством или мучениями для потерпевшего; общеопасным способом; по найму; из хулиганских побуждений; по мотивам политической, идеологической, расовой, национальной или религиозной ненависти или вражды либо по мотивам ненависти или вражды в отношении какой-либо социальной группы; в целях использования органов или тканей потерпевшего, - наказываются тишением свободы на срок до десяти лет с ограничением свободы на срок до двух лет либо без такового;

$\boldsymbol{a}_{3}$ - деяния, предусмотренные частями первой или второй настоящей статьи, если они совершены: группой лиц, группой лиц по предварительному сговору или организованной группой; в отношении двух или более лиц, - наказываются тишением свободы на срок до двенадиати лет с ограничением свободы на срок до двух лет либо без такового;

$\boldsymbol{a}_{\mathbf{4}}$ - деяния, предусмотренные частями первой, второй или третьей настоящей статьи, повлекшие по неосторожности смерть потерпевшего, - наказываются тишением свободы на срок до пятнадиати лет с ограничением свободы на срок до двух лет либо без такового.

\section{Смягчающие обстоятельства:}

$\boldsymbol{b}_{\mathbf{1}}$ - совершение впервые преступления небольшой или средней тяжести вследствие случайного стечения обстоятельств;

$\boldsymbol{b}_{2}$ - несовершеннолетие виновного;

$\boldsymbol{b}_{3}$ - беременность;

$\boldsymbol{b}_{\mathbf{4}}$ - наличие малолетних детей у виновного; $\boldsymbol{b}_{5}$ - совершение преступления в силу стечения тяжелых жизненных обстоятельств либо по мотиву сострадания;

$\boldsymbol{b}_{6}$ - совершение преступления в результате физического или психического принуждения либо в силу материальной, служебной или иной зависимости;

$\boldsymbol{b}_{7}$ - совершение преступления при нарушении условий правомерности необходимой обороны, задержания лица, совершившего преступление, крайней необходимости, обоснованного риска, исполнения приказа или распоряжения;

$\boldsymbol{b}_{\mathbf{8}}$ - противоправность или аморальность поведения потерпевшего, явившегося поводом для преступления;

$\boldsymbol{b}_{\mathbf{9}}$ - явка с повинной, активное способствование раскрытию и расследованию преступления, изобличению и уголовному преследованию других соучастников преступления, розыску имущества, добытого в результате преступления;

$\boldsymbol{b}_{\mathbf{1 0}}$ - оказание медицинской и иной помощи потерпевшему непосредственно после совершения преступления, добровольное возмещение имущественного ущерба и морального вреда, причиненных в результате преступления, иные действия, направленные на заглаживание вреда, причиненного потерпевшему.

Отягчающие обстоятельства:

$\boldsymbol{c}_{\mathbf{1}}$ - рецидив преступлений;

$\boldsymbol{c}_{2}$-наступление тяжких последствий в результате совершения преступления;

$\boldsymbol{c}_{3}$ - совершение преступления в составе группы лиц, группы лиц по предварительному сговору, организованной группы или преступного сообщества (преступной организации);

$\boldsymbol{c}_{\mathbf{4}}$ - особо активная роль в совершении преступления;

$\boldsymbol{c}_{5}$ - привлечение к совершению преступления лиц, которые страдают тяжелыми психическими расстройствами либо находятся в состоянии опьянения, а также лиц, не достигших возраста, с которого наступает уголовная ответственность;

$\boldsymbol{c}_{\boldsymbol{6}}$ - совершение преступления по мотивам политической, идеологической, расовой, национальной или религиозной ненависти 
или вражды либо по мотивам ненависти или вражды в отношении какой-либо социальной группы;

$\boldsymbol{c}_{7}$ - совершение преступления из мести за правомерные действия других лиц, а также с целью скрыть другое преступление или облегчить его совершение;

$\boldsymbol{c}_{\boldsymbol{8}}$ - совершение преступления в отношении лица или его близких в связи с осуществлением данным лицом служебной деятельности или выполнением общественного долга;

$\boldsymbol{c}_{\boldsymbol{9}}$ - совершение преступления в отношении женщины, заведомо для виновного находящейся в состоянии беременности, а также в отношении малолетнего, другого беззащитного или беспомощного лица либо лица, находящегося в зависимости от виновного;

$\boldsymbol{c}_{\mathbf{1 0}}$ - совершение преступления с особой жестокостью, садизмом, издевательством, а также мучениями для потерпевшего;

$\boldsymbol{c}_{\mathbf{1 1}}$ - совершение преступления с использованием оружия, боевых припасов, взрывчатых веществ, взрывных или имитирующих их устройств, специально изготовленных технических средств, наркотических средств, психотропных, сильнодействующих, ядовитых и радиоактивных веществ, лекарственных и иных химико-фармакологических препаратов, а также с применением физического или психического принуждения;

$\boldsymbol{c}_{\mathbf{1 2}}$ - совершение преступления в условиях чрезвычайного положения, стихийного или иного общественного бедствия, а также при массовых беспорядках, в условиях вооруженного конфликта или военных действий;

$\boldsymbol{c}_{13}$ - совершение преступления с использованием доверия, оказанного виновному в силу его служебного положения или договора;

$\boldsymbol{c}_{\mathbf{1 4}}$ - совершение преступления с использованием форменной одежды или документов представителя власти;

$\boldsymbol{c}_{15}$ - совершение умышленного преступления сотрудником органа внутренних дел;

$\boldsymbol{c}_{\mathbf{1 6}}$ - совершение преступления в отношении несовершеннолетнего (несовершеннолетней) родителем или иным лицом, на которое законом возложены обязанности по воспитанию несовершеннолетнего (несовершен- нолетней), а равно педагогическим работником или другим работником образовательной организации, медицинской организации, организации, оказывающей социальные услуги, либо иной организации, обязанным осуществлять надзор за несовершеннолетним (несовершеннолетней);

$\boldsymbol{c}_{\mathbf{1 7}}$ - совершение преступления в целях пропаганды, оправдания и поддержки терроризма.

$\min =0 ; \max =16$.

Коэффициенты тяжести смягчающих обстоятельств (выведены путем экспертной оценки):

$$
\begin{aligned}
& k_{1} \ldots k_{6}=0,68 ; k_{7} \ldots k_{10}=0,44 ; \\
& k_{1+\ldots+} k_{6}=0,68 ; k_{7+\ldots+} k_{10}=0,44 .
\end{aligned}
$$

Коэффициенты тяжести отягчающих обстоятельств (выведены путем экспертной оценки):

$$
\begin{aligned}
& k_{1} \ldots k_{9}=0,9 ; k_{7} \ldots k_{10}=1 ; \\
& k_{1+\ldots+} k_{9}=0,9 ; k_{7+\ldots+} k_{10}=1 .
\end{aligned}
$$

quality - ограничение свободы сроком до двух лет.

\section{ПРАВИЛА}

Правило 1:

If $\left(a_{1}\right)$ and $\left(b_{1}\right.$ and $b_{2}$ and $\left.\ldots b_{10}\right)$ then $(\mathrm{min})$;

\section{Правило 2:}

If $\left(a_{1}\right)$ and $\left(b_{1}\right.$ and $b_{2}$ and $\left.\ldots b_{6}\right)$ then

$\left(\min +(\max -\min ) *\left(k_{1+\ldots+} k_{6}\right)\right)$.

\section{Правило3:}

If $\left(a_{1}\right)$ and $\left(b_{7}\right.$ and $\left.\ldots b_{10}\right)$ then

$\left(\min +(\max -\min ) *\left(k_{7+\ldots+} k_{10}\right)\right)$.

\section{Правило 4:}

If $\left(a_{2}\right.$ or $\left.\ldots a_{n}\right)$ and $\left(b_{1}\right.$ and $b_{2}$ and $\left.\ldots b_{6}\right)$ then

(min) and quality;

\section{Правило 5:}

If $\left(a_{2}\right.$ or $\left.\ldots a_{n}\right)$ and $\left(b_{1}\right.$ and $b_{2}$ and $\left.\ldots b_{n}\right)$

then quality;

\section{Правило 6:}

If $\left(a_{1}\right)$ and $\left(c_{1}\right.$ and $c_{2}$ and $\left.\ldots c_{17}\right)$ then (max);

\section{Правило 7:}

If $\left(a_{2}\right.$ or $\left.\ldots a_{n}\right)$ and $\left(c_{1}\right.$ and $c_{2}$ and $\left.\ldots c_{17}\right)$ then

(max) and quality; 


\section{Правило 8:}

If $\left(a_{2}\right.$ or $\left.\ldots a_{n}\right)$ and $\left(b_{1}\right.$ and $b_{2}$ and $\left.\ldots b_{10}\right)$

and $\left(c_{1}\right.$ and $c_{2}$ and $\left.\ldots c_{17}\right)$ then

$\left(\left(\min +(\max -\min ) *\left(k_{1}+k_{2}+\ldots k_{n}\right)\right)\right.$

and quality $\left.*\left(k_{1}+k_{2}+\ldots k_{n}\right)\right)$.

\section{ОСНОВНЫЕ ВЫВОДЫ}

Разработка продукционных правил оказалась самым трудоемким этапом. При разборе уголовных дел выяснилось, что чаще всего встречаются случаи с множеством компонентов, с которыми работают сразу несколько продукционных правил.

Предложенные подходы для разработки модели определения зависимостей и оценки результатов исследования позволяют обосновать практическое применение метода парных сравнений к обстоятельствам уголовного дела, а также практическое применение алгоритма Мамдани для разработки процедуры поддержки принятия решений.

Следующий этап предполагает решение следующих задач для создания модели определения зависимостей, на базе которой будет разработана процедура поддержки принятия решений и программная реализация:

1. Определение методов для нечетких высказываний в уголовных делах со сложной структурой и множеством компонентов.

2. Определение экспертных оценок, вероятностных, лингвистических весов выбора к продукционным правилам для конкретных статей УК РФ.

3. Сбор и обработка дополнительных статистических данных по уголовным делам.

4. Разработка приложения для всех обстоятельств и их весов и квалификации преступлений.
5. Сравнение результата с предварительными гипотезами.

Результаты исследования можно будет использовать для создания тренажеров, обучающих систем профессиональной деятельности, что позволит свести процесс вынесения судебных решений к формальной оценке, уменьшая, тем самым, присутствующий субъективизм.

\section{СПИСОК ЛИТЕРАТУРЫ}

1. Уголовно-процессуальный кодекс РФ от 18 декабря 2001 г. №174-Ф3 // Российская газета. - 22 декабря 2001 г. - № 249.

2. Уголовный кодекс РФ от 13 июня 1996 г. № 63-Ф3 // Собрание законодательства Российской Федерации. - 17 июня 1996 г. - № 25. Ст. 2954.

3. Харченко, Т. Ю. Разработка формальной процедуры поддержки принятия судебных решений / Т. Ю. Харченко, И. Е. Воронина // Вестник Воронеж. гос. ун-та. Сер. Системный анализ и информационные технологии. 2012. - № 1. - С. 96-101.

4. Харченко, Т. Ю. Разработка количественного подхода и метода экспертного оценивания для модели определения зависимостей и оценки результатов судебных решений / Т. Ю. Харченко, И. Е. Воронина // Эвристические алгоритмы и распределенные вычисления. - Самара, 2015. -Т. 2. С. 11-20.

5. Борисов, В. В. Нечеткие модели и сети / В. В. Борисов, В. В. Круглов, А. С. Федулов. М. : Горячая линия - Телеком, 2007. - 284 c.

6. Матвеев, М. Г. Модели и методы искусственного интеллекта. Применение в экономике: учеб. пособие / М. Г. Матвеев, А. С. Свиридов, Н. А. Алейникова. - М. : Финансы и статистика, 2008. - 448 с. 
Харченко Татьяна Юрьевна - аспирант кафедры программного обеспечения и администрирования информационных систем факультета ПММ ВГУ.

Тел.: 8-910-343-09-02

E-mail: harchenko-tatyan@mail.ru

Воронина Ирина Евгеньевна - д-р техн. наук, доцент, профессор кафедры программного обеспечения и администрирования информационных систем факультета ПММ ВГУ. Тел.: 8-903-650-4410

E-mail: irina.voronina@gmail.com
Kharchenko Tatyana Yu. - 4-th year postgraduate of Department of Applied Mathematics, Computer Science \& Mechanics, Subdepartment of Software and Administration of Information System.

Tel.: 8-910-343-09-02

E-mail: harchenko-tatyan@mail.ru

Voronina Irina Ev. - Ph.D. in technical sciences, associate professor, Department of Applied Mathematics, Computer Science \& Mechanics, Subdepartment of Software and Administration of Information System.

Tel.: 8-903-650-4410

E-mail: irina.voronina@gmail.com 